\title{
Distribuição espacial da relação precipitação/número de dias de chuva em Campo Grande - MS
}

\author{
Amaury de Souza; \\ Hamilton Germano Pavão ${ }^{\mathrm{I}}$ \\ Giancarlo Lastoria ${ }^{\text {II }}$ \\ Sandra Garcia Gabas ${ }^{\text {II }}$ \\ Antonio Conceição Paranhos Filho II \\ Guilherme Henrique Cavazzana ${ }^{\text {III }}$.
}

IDepto de Física, Centro de Ciências Exatas e Tecnologia, Universidade Federal de Mato Grosso do Sul, caixa postal 549, CEP 79070-900, Campo Grande-MS, Brasil, amaury@nin.ufms.br; pavão@nin.ufms.br;

II Depto de Hidráulica e Transportes, Centro de Ciências Exatas e Tecnologia, Universidade Federal de Mato Grosso do Sul, caixa postal 549, CEP 79070-900, Campo Grande-MS Brasil, lastoria@nin.ufms.br; sandragabas@nin.ufms.br; toniparanhos@gmail.com;

${ }^{\text {III }}$ Mestrando do Programa de Pós Graduação em Tecnologias Ambientais, Centro de Ciências Exatas e Tecnologia, Universidade Federal de Mato Grosso do Sul, Brasil. cavazzana.ea@gmail.com

\begin{abstract}
The knowledge of the type and characteristics of the precipitation are very important, mainly for the agricultural planning. And that of the characteristic precipitation can be made knowing the relationship of the precipitation totals with the number of rainfall days happened. In this context, the objective of this study is to characterize the precipitation in whole the city Campo Grande the State of Mato Grosso do Sul establishing a index the two variables. The study was performed using totals monthly data regarding precipitation and number of rainfall days obtained from meteorological stations, in the period of $1970-2008$, for the quarters of jan-FebMar, Apr-May-jun, jul-Aug-Sep and out-nov-Dec. The results show that the precipitation index/number of days of rain Q3 increases for the fourth.
\end{abstract}

Palavras-Chave: precipitação, número de dias de chuva, Mato Grosso do Sul. 


\section{Introdução}

As mudanças no clima podem acarretar significativos impactos nos setores naturais, social e econômico. Os extremos climáticos associados à temperatura e precipitação podem também afetar consumo de energia, conforto humano e turismo (Subak et al., 2000; Qian e Lin, 2005).

$\mathrm{O}$ aumento nas perdas econômicas devido a extremos de tempo e, especialmente, $\mathrm{o}$ aumento nas perdas de vidas, tem sido regularmente notícias de jornais, despertando o interesse da comunidade científica em estudar tais fenômenos (Kostopoulo e Jones, 2005).

Mudanças na precipitação têm implicações no ciclo hidrológico e recursos hídricos. Espera-se que as mudanças climáticas alterem a temperatura média e os valores da precipitação e que aumentem a variabilidade dos eventos de precipitação, que poderão causar inundações e secas mais intensas e freqüentes. Qian e Lin (2005) afirmam que a freqüência e a persistência das secas deverá ser uma das conseqüências do aquecimento global. Walsh e Pittock (1998) sugeriram que as potenciais mudanças nas tempestades tropicais, furacões e eventos extremos de chuva são um resultado das mudanças climáticas. Em geral, muitas atividades econômicas e processos ambientais são altamente dependentes da precipitação. No Nordeste do Brasil (NEB), as atividades agrícolas, quase que em sua totalidade, são baseadas na precipitação e o conhecimento de sua variabilidade é de extrema importância.

O Estado do Mato Grosso do Sul está localizado em latitudes médias, no extremo oeste do Brasil. Devido a esta localização o Estado sofre influência nas suas condições climáticas, tanto, de fenômenos oriundos de altas latitudes, por exemplo, os sistemas frontais, como também de fenômenos de latitudes baixas. Sobretudo, estes não são os únicos a influenciar o clima da região, o El Niño Oscilação Sul contribui muito para variabilidade da precipitação no Estado. CARDOSO \& SILVA DIAS (2002) sugerem que as anomalias de TSM nos oceanos Atlântico e Pacífico possuem relações significativas com a precipitação nas Regiões Sul, Sudeste e Centro Oeste do Brasil e, com isso, podem ser mais um dos fatores que influenciam a precipitação nestas regiões.

Ao longo do território do Mato Grosso do Sul a precipitação caracteriza-se pela sua homogeneidade, não há nenhum local onde a precipitação acumulada seja deficiente ou apresenta-se com excesso, a precipitação pluvial anual média é da ordem de $1.500 \mathrm{~mm}$, sendo inferior a este valor na metade sul do Estado e superior a esta média, na metade norte (NIMER, 1979). Segundo FERREIRA \& NERY (1999), a distribuição da precipitação no estado do Mato Grosso do Sul, apresenta uma maior concentração nas regiões oeste e nordeste do Estado e uma menor concentração na região noroeste. Por possuir uma economia principalmente voltada à agricultura, o enriquecimento desta região está diretamente ligado ao clima, principalmente à precipitação, que é uma das variáveis meteorológicas mais importantes para o bom desenvolvimento das culturas agrícolas.

Diante disso, diversos trabalhos têm sido realizados caracterizando a distribuição espacial e temporal da precipitação pluvial, por exemplo, MACHADO (1950), MORENO (1961) e BURIOL et al (1977). O conhecimento do tipo e características da precipitação são muito importantes, não só no planejamento agrícola, mas também no acúmulo e manuseio da água, bem como na Construção Civil.E, a característica da precipitação pode ser feita, de certa forma, conhecendo a relação dos totais de precipitação com o número de dias de chuvas ocorridos e essa relação pode constituir-se em um índice que, em vias de regra caracteriza o tipo de precipitação pluvial ocorrido em um local.

Como a precipitação medida em estações meteorológicas, nem sempre é um bom parâmetro para avaliarmos se a disponibilidade hídrica em determinado período é suficiente para o atendimento das culturas agrícolas; com o número de dias de chuva, é possível ter-se uma idéia da intensidade da precipitação, pois ao analisar o mesmo total de chuva em 
intervalos de tempo distintos, revela qual a intensidade e a variabilidade quantitativa da precipitação. ARAUJO \& DINIZ (2004) estudaram a relação do número de dias de chuva e o evento El Niño na região de Pelotas, onde verificou-se que os eventos El Niños aumentam o número de meses com elevado número de dias de chuva como também aumentam os totais mensais de precipitação. O objetivo deste trabalho é caracterizar a precipitação em todo o Estado do Mato Grosso do Sul estabelecendo um índice relacionando as duas variáveis.

\section{Material e Métodos}

Foram utilizados neste trabalho dados de totais médios mensais de precipitação e de número de dias de chuva, provenientes das estações meteorológicas distribuídas em todo o Estado, para os trimestres de jan-fev-mar, abr-mai-jun, jul-ago-set e out-nov-dez.

Os dados das estações meteorológicas foram obtidos junto ao Instituto Nacional de Meteorologia - INMET, do Ministério da Agricultura, Pecuária e Abastecimento (MAPA), para o período de 1970 à 2008. Primeiramente, foram calculados a soma trimestral para os meses janeiro-fevereiro-março, abril-maio-junho, julho-agosto-setembro e outubronovembro-dezembro, tanto para os dados de precipitação como para os dados de números de dias de chuva. Em um segundo momento, foi feito a divisão da soma trimestral da precipitação pela soma trimestral do número de dias de chuva, estabelecendo, desta forma, um índice a fim de caracterizar a chuva.

A partir de então foram construídos mapas desse índice para a visualização dos resultados.

A média dos números de dias de chuva também foi calculada, para confrontarmos a distribuição do número de dias de chuva com o índice precipitação/número de dias de chuva.

\section{Resultados e Discussões}

Na Figura 1, analisando o índice caracterizado pela relação precipitação/número de dias de chuva para os meses de janeiro, fevereiro e março, observa-se o valor de 10,3; com uma precipitação de 447,7 mm e um número de dias chuvosos de 43,3; já para o segundo trimestre chuvoso, março,abril,maio atinge o valor de 9,6; com uma precipitação de $253 \mathrm{~mm}$ e um número de dias chuvosos de 26,3; no terceiro trimestre, julho,agosto,setembro assume o valor de 7,4 o mais baixo do período, com uma precipitação de $100,9 \mathrm{~mm}$ e um número de dias chuvosos de 13,7; e para o quarto trimestre assume o valor de 12,3 o mais alto, com uma precipitação de $514,3 \mathrm{~mm}$ e um número de dias chuvosos de 41,7. Por via de regra, onde existirem os maiores valores do índice, tem-se uma precipitação mais forte em poucos números de dias de chuva, ocasionando um índice mais elevado, enquanto que os menores valores do índice indicam pouca precipitação em poucos números de dias de chuva ou pouca precipitação em muitos números de dias de chuva. 


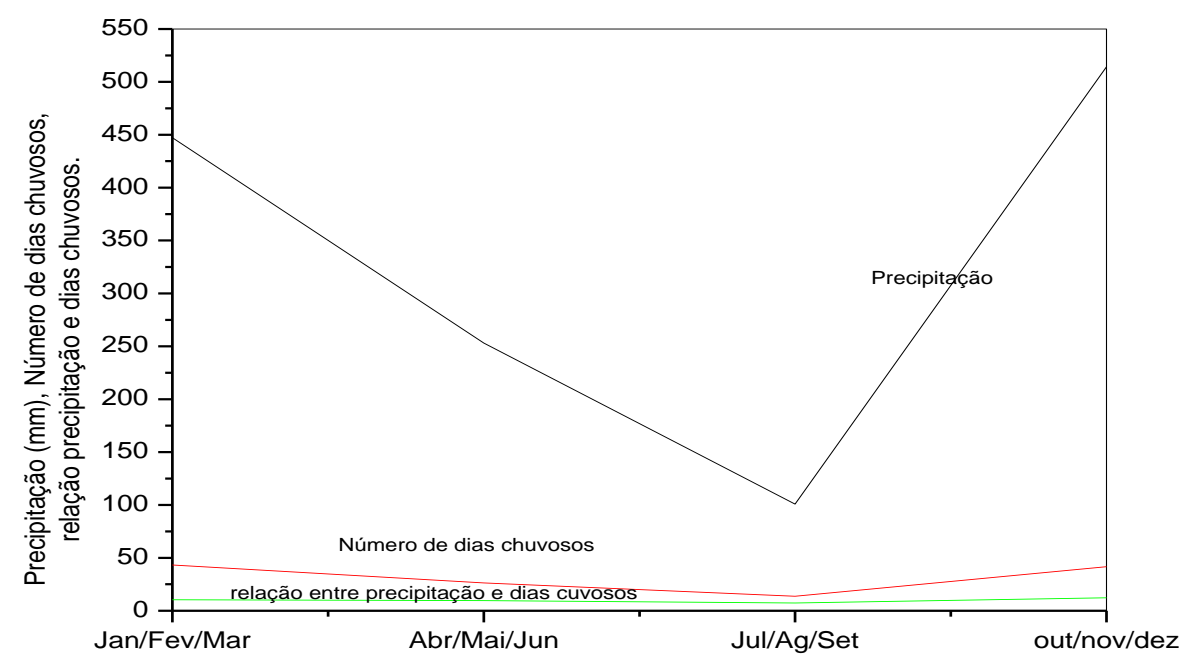

Figura 1: Relação entre: precipitação-número de dias de chuva para os meses jan-fev-mar (a), abr-mai-jun (b), jul-ago-set (c) e out-nov-dez (d), para Campo Grande- MS.

A Figura 2 mostra a relação do número de dias de chuvas em função dos intervalos de frequiência, que foram divididos em $5 \mathrm{em} 5 \mathrm{~mm}$ para a bacia de Campo Grande e pode-se perceber que o maior número de dias sem chuvas é de 116 dias e com baixa intensidade no intervalo de 0,01-5,0 $\mathrm{mm}$ acontece 153 vezes em média, já chuvas com intensidades superiores a $20 \mathrm{~mm}$ ocorrem poucas vezes, conforme figura 2. Campo Grande tem uma precipitação média anual de 1315 mm distribuída em 125 dias com chuvas, com uma média de $10 \mathrm{~mm}$ por dias chuvoso.

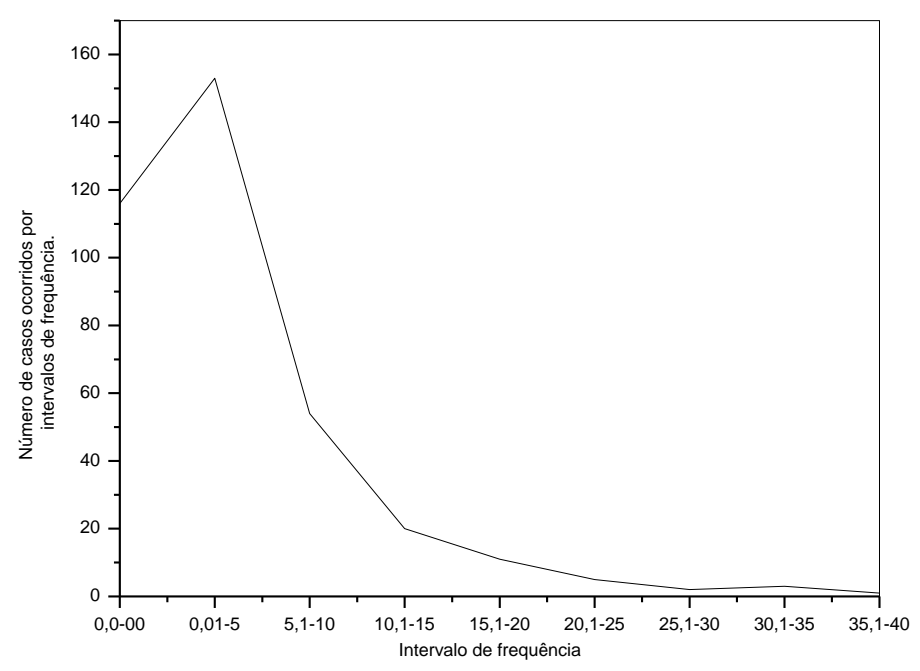

Figura 2: Número médio de dias de chuvas em função dos intervalos para a bacia de Campo Grande-MS, período de 1970-2008.

\section{Conclusões}

Analisando o índice precipitação/número de dias de chuva, este aumenta do terceiro trimestre para o quarto trimestre, voltando a diminuir no primeiro e segundo trimestre, atingindo seu valor mínimo no terceiro trimestre, quando temos poucos dias de chuvas e 
baixo índice de precipitação. O trimestre mais chuvoso é o quarto, onde caracteriza duas estações bem definidas, uma chuvosa e outra seca.

\section{Referências Bibliográficas}

ARAUJO, S.B.; DINIZ, G.B. Relação do evento El Niño e o número de dias de chuva na região de Pelotas - RS. In: Congresso Brasileiro De Meteorologia, 13., 2004 Fortaleza: SBMet, 2004.

BURIOL, G.A.; ESTEFANEL, V.;FERREIRA, M. Cartas mensais e anual das chuvas do estado do Rio Grande do Sul. Revista do Centro de Ciências Rurais, Santa Maria, v.7, n.1, p.55-82. 1977.

CARDOSO, A.O.; SILVA DIAS, P.L. Identificação de trimestres extremos no regime pluviométrico do Sul e Sudeste do Brasil e relação com a TSM. In: Congresso Brasileiro De Meteorologia, 12., 2002, Foz de IguaçuPR.: SBMet, 2002.

FERREIRA, J.H.D.; NERY, J.T. Análise estatística da precipitação pluviométrica no Estado do Rio Grande do Sul. In: Congresso Brasileiro De Agrometeorologia, 11; 1999, Florianópolis - SC. SBAgro 1999.

FONTANA, D.C; ALMEIDA, T.S. Climatologia do número de dias de chuva com precipitação pluvial no Estado do Rio Grande do Sul. Revista Brasileira de Agrometeorologia, Santa Maria -RS, v.10, n.1, p.135-145, 2002.

MACHADO, F.P. Contribuição ao estudo do clima do Rio Grande do Sul. Rio de Janeiro: IBGE, 1950. 91p.

MORENO, J.A. Clima do Rio Grande do Sul. Porto Alegre: Secretaria da Agricultura do Estado do Rio Grande do Sul. 1961. 30p.

NIMER, E. Climatologia do Brasil. Rio de Janeiro: IBGE, 1979. 422p.

SUBAK, S., PALUTIKOF, J. P., AGNEW, M. D., WATSON, S. J., BENTHAM, C. G., CANNELL, M. G. R., HULME, M., McNALlY, S., THORNES, J. E., WAUGHRAY, D., WOODS, J. C. The impact of the anomalous weather of 1995 on the UK economy. Climatic Change, v. 44, p. 1-26, 2000.

QIAN, W., LIN, X. Regional trends in recent precipitation indices in China. Meteorology and Atmospheric Physics, v. 90, p. 193-207, 2005.

KOSTOPOUlO, E., JONES, P. D. Assesment of climate extremes in the Eastern Mediterrenean. Meteorology and Atmospheric Physics, v. 89, p. 69-85, 2005.

WALSH, K., PITTOCK, A. B. Potential changes in tropical storms, hurricanes, and extreme rainfall events as a result of climate change. Climatic Change, v. 39, p. 199-213, 1998. 